\title{
SYK expression in monomorphic epitheliotropic intestinal T-cell lymphoma
}

\author{
Grit Mutzbauer $^{1}$, Katja Maurus ${ }^{1}$, Clara Buszello ${ }^{1}$, Jordan Pischimarov ${ }^{1}$, Sabine Roth ${ }^{1}$, \\ Andreas Rosenwald ${ }^{1,2}$, Andreas Chott ${ }^{3}$ and Eva Geissinger ${ }^{1,2}$ \\ ${ }^{1}$ Institute of Pathology, University of Wuerzburg, Wuerzburg, Germany; ${ }^{2}$ Comprehensive Cancer Center \\ Mainfranken, University and University Hospital, Wuerzburg, Germany and ${ }^{3}$ Institute of Pathology and \\ Microbiology, Wilhelminenspital, Vienna, Austria
}

\begin{abstract}
Monomorphic epitheliotropic intestinal T-cell lymphoma (MEITL), formerly known as type II enteropathy associated T-cell lymphoma (type II EATL), is a rare, aggressive primary intestinal T-cell lymphoma with a poor prognosis and an incompletely understood pathogenesis. We collected 40 cases of MEITL and 27 cases of EATL, formerly known as type I EATL, and comparatively investigated the T-cell receptor (TCR) itself and associated signaling molecules using immunohistochemistry, amplicon deep sequencing and bisulfite pyrosequencing. The TCR showed both an $\alpha \beta$-T-cell origin $(30 \%)$ and a $\gamma \delta$-T-cell derivation $(55 \%)$ resulting in a predominant positive TCR phenotype in MEITL compared with the mainly silent TCR phenotype in EATL (65\%). The immunohistochemical expression of the spleen tyrosine kinase (SYK) turned out to be a distinctive feature of MEITL (95\%) compared with EATL ( $0 \%$ ). Aberrant SYK overexpression in MEITL is likely caused by hypomethylation of the SYK promoter, while no common mutations in the SYK gene or in its promoter could be detected. Using amplicon deep sequencing, mutations in DNMT3A, IDH2, and TET2 were infrequent events in MEITL and EATL. Immunohistochemical expression of linker for activation of T-cells (LAT) subdivided MEITL into a LAT expressing subset $(33 \%)$ and a LAT silent subset $(67 \%)$ with a potentially earlier disease onset in LAT-positive MEITL. Modern Pathology (2018) 31, 505-516; doi:10.1038/modpathol.2017.145; published online 20 October 2017
\end{abstract}

Monomorphic epitheliotropic intestinal T-cell lymphoma (MEITL), originally described by Chott et al. ${ }^{1}$ and formerly known as type II enteropathy associated T-cell lymphoma (type II EATL), is recognized as a distinct entity of primary intestinal T-cell lymphoma in the 2017 revision of the WHO classification of hematopoietic and lymphoid tumors. ${ }^{2}$ This rare and aggressive, extranodal lymphoma is predominantly found in Asia and characterized by a small to mediumsized, usually monomorphic T-cell population with expression of CD8, CD56, and megakaryocyteassociated tyrosine kinase. The neoplastic lymphocytes are thought to be derived from intestinal intraepithelial lymphocytes. ${ }^{1,3-6}$ The lymphoma cells display a striking intraepithelial spread, whereas features of enteropathy in terms of a preexisting celiac disease are unusual. ${ }^{6}$ MEITL carries a very poor prognosis aggravated by the lack of an established standard therapy. ${ }^{7}$ The pathogenesis of MEITL

Correspondence: Professor E Geissinger, MD, Institute of Pathology, University of Wuerzburg, Josef-Schneider-Str. 2, Wuerzburg 97080, Germany.

E-mail: Geissinger@mail.uni-wuerzburg.de

Received 28 May 2017; revised 2 September 2017; accepted 11 September 2017; published online 20 October 2017 gradually begins to emerge. With regard to chromosomal copy number variations, gains of the chromosomal region 9q33-q34 and an amplification of chromosome locus 8q24 were most commonly reported. ${ }^{6,8-10}$ Novel genetic insights were recently published showing recurrent SETD2 alterations implying an epigenetic deregulation ${ }^{11,12}$ as well as frequent mutations in $S T A T 5 B$ and $J A K 3$ providing evidence that an alteration of cytokine signaling pathways has a decisive role in the lymphomagenesis of MEITL. ${ }^{13-15}$ We here report on the consistent expression of the spleen tyrosine kinase (SYK) in MEITL pointing to altered T-cell receptor (TCR) signaling as another pillar in the pathogenesis of MEITL.

\section{Materials and methods}

Study Sets

A total of 67 cases, consisting of 40 MEITL and 27 EATL cases, were retrieved from the files of the Institute of Pathology, University of Wuerzburg, Germany $(n=34)$ and from the files of the Institute of Pathology and Microbiology, Wilhelminenspital and Vienna General Hospital, Vienna, Austria 
( $n=33)$ covering the years 1989 through 2013. The whole study set was used for the SYK and TCR analyses and is referred to as 'extended study set' ( $n_{\text {total }}=67, n_{\text {MEITL }}=40$, and $n_{\text {EATL }}=27$; Supplementary Table 1). Additional analyses were carried out in only a subset of these cases due to limited material. This subset is called 'core study set' $\left(n_{\text {total }}=34, \quad n_{\text {MEITL }}=20, \quad n_{\text {EATL }}=14 ;\right.$ Table 1$)$. The samples were on hand as formalin-fixed, paraffinembedded tissue blocks. Tissue sections were stained with routine stains (hematoxylin and eosin, Giemsa, periodic acid Schiff) and an appropriate immunohistochemical panel in addition to an EBER in situ hybridization to establish the diagnosis according to the current WHO classification (Supplementary Table 2). ${ }^{2,16}$ For inclusion in this study, all cases were reviewed by experienced hematopathologists (AR, AC, EG). Approval for the study was obtained from the ethics committees, Medical Faculty, University of Wuerzburg, Germany and Medical University of Vienna, Austria. Moreover, medical records were reviewed for preexisting celiac disease, site of involvement, treatment and outcome in all cases of the core study set.

\section{Immunohistochemical Analysis}

Conventional immunohistochemical single stains were performed according to standard protocols using the Advance HRP detection kit (Dako, Hamburg, Germany). We extensively analyzed the expression of SYK and zeta-chain-associated protein kinase of $70 \mathrm{kDa}$ (ZAP-70) as well as the $\beta$-chain (TCR Beta F1) and the $\gamma$-chain (TCR C $\gamma \mathrm{M} 1$ ) of the TCR. Moreover, we investigated the expression of the following key enzymes and scaffold proteins participating in the proximal TCR signaling cascade (Figure 1): leukocyte C terminal Src kinase (LCK), FYN protooncogene (FYN), linker for activation of T-cells (LAT), SRC homology 2 domain-containing leukocyte protein of $76 \mathrm{kDa}$ (SLP-76), phospholipase $\mathrm{C} \gamma 1$ (PLC $\gamma 1$ ), VAV1 guanine nucleotide exchange factor (VAV1) and hematopoietic progenitor kinase 1 (HPK1). Detailed information (dilution, pretreatment, source) of the applied primary antibodies are given in Supplementary Table 3. All stains were assessed semi-quantitatively using two categories (negative and positive). A stain was defined as positive if the staining result was moderately or strongly positive in at least $30 \%$ of lymphoma cells. Otherwise the staining results were considered as negative. Immunoreactivity on background lymphocytes served as positive internal control.

\section{DNA Isolation}

Genomic DNA was isolated from formalin-fixed, paraffin-embedded tissue sections using the Qiagen DNeasy Blood \& Tissue Kit (Qiagen, Hilden, Germany) according to the manufacturer's instructions. Manual microdissection of the tissue was performed for tumor cell enrichment as required.

\section{Amplicon Deep Sequencing}

According to the manufacturer's guidelines for formalin-fixed, paraffin-embedded extracted genomic DNA, 39 amplicons with a mean size of $368 \mathrm{bp}$ (Supplementary Table 4) were generated in three polymerase chain reaction (PCR) steps, including concentration, enrichment via the 48.48 Access Array IFC (Fluidigm, Amsterdam, The Netherlands), and barcoding, using $50 \mathrm{ng}$ of genomic DNA per sample. The amplicon sequencing was performed on the Roche -454 Sequencing Platform using the workflow recommended by the manufacturer's manuals. Briefly, 12 equimolar sample specific amplicon pools were combined, amplified by an emulsion PCR with a copy per bead ratio of 1:1 and sequenced on the GS Junior instrument (Roche Applied Science, Penzberg, Germany). All data were generated with the instrument software. Image processing and amplicon pipeline analysis was done using default settings of the GS Run Browser software. Demultiplexing, sequence alignment to the reference genome (GRCh37/hg19) and variant capture was performed using standard settings of the GS Amplicon Variant Analyzer software. With respect to the formalin-fixed, paraffin-embedded extracted genomic DNA quality and the manual processing steps the detection threshold for a variant was set to a minimum of $5 \%$ variant allele frequency with at least 5 reads containing this variant. All nonsynonymous variants which were located outside introns and exhibited at least two cases matching the filter setting were taken into account for further analyses including a visual review with the Integrative Genomic Viewer (GRCh37/hg19), annotation with the SeattleSeq Variation Annotation 138 and functional prediction via PolyPhen and SIFT score (Supplementary Table 5). The two cell lines KMS12BM and JJN3 served as internal controls and were purchased from the German Collection of Microorganisms and Cell Cultures (DSMZ, Braunschweig, Germany). They were cultured and prepared as previously described. ${ }^{17}$

\section{Sanger Sequencing}

Genomic DNA was amplified by a touchdown PCR combined with a hot start method using the AmpliTaq Gold DNA polymerase (ThermoFisher Scientific, Waltham, MA, USA) and primers listed in Supplementary Table 6 . The PCR products were visualized by $2 \%$ agarose gel electrophoresis. The amplificates were purified using the MinElute PCR Purification Kit (Qiagen, Hilden Germany) and then directly sequenced with the BigDye Terminator v3.1 Cycle Sequencing Kit (Applied Biosystems, Foster City, CA, USA) on a 16capillary electrophoresis instrument (Applied Biosystems, Foster City, CA, USA). Sequences were aligned to the reference genome (GRCh37/hg19) and analyzed using ChromasPRO software (Technelysium Pty Ltd, 


\begin{tabular}{|c|c|c|c|c|c|c|c|c|c|c|c|c|c|c|c|c|c|c|c|c|}
\hline Entity & Subsets & Case & Sex & $\begin{array}{l}\text { Age } \\
\text { (years) }\end{array}$ & $\begin{array}{l}\text { Preex. } \\
C D\end{array}$ & $\begin{array}{l}\text { Site of } \\
\text { involvement }\end{array}$ & Treatment & $\begin{array}{l}\text { Outcome } \\
\text { (months) }\end{array}$ & $T C R \beta \mathrm{F} 1$ & $T C R \gamma$ & LCK & $F Y N$ & $Z A P-70$ & $\begin{array}{l}\text { SYK } \\
\text { EP573Y }\end{array}$ & $\begin{array}{l}\text { SYK } \\
\text { SPM147 }\end{array}$ & $L A T$ & PLC $\gamma 1$ & $S L P-76$ & $V A V 1$ & HPK1 \\
\hline MEITL & LAT silent & M01 & $\mathrm{m}$ & 59 & $\begin{array}{l}\text { n.r. } \\
\text { CD }\end{array}$ & $\begin{array}{l}\text { SI, LI, } \\
\text { supraclavicular } \\
\text { area }\end{array}$ & $\mathrm{SR}+\mathrm{CT}$ & DOD, 13 & - & - & - & - & + & + & + & - & - & + & n.an. & + \\
\hline MEITL & LAT silent & M02 & $\mathrm{f}$ & 50 & $\begin{array}{l}\text { n.r. } \\
\text { CD }\end{array}$ & SI (jejunum) & $\begin{array}{l}\mathrm{SR}+\mathrm{CT}+ \\
\mathrm{PBSCT}\end{array}$ & n.a. & - & - & + & - & + & + & + & - & - & + & + & + \\
\hline MEITL & LAT silent & M03 & $\mathrm{m}$ & 75 & $\begin{array}{l}\text { n.r. } \\
\text { CD }\end{array}$ & SI, LI & SR & DOD, 20 & - & + & + & + & + & + & + & - & + & + & + & + \\
\hline MEITL & LAT silent & M04 & $\mathrm{m}$ & 62 & $\begin{array}{l}\text { n.r. } \\
\text { CD }\end{array}$ & $\begin{array}{l}\text { SI (jejunum, } \\
\text { ileum), LI, } \\
\text { bladder, brain, } \\
\text { spermatic duct, } \\
\text { pulmonary LN, } \\
\text { lung }\end{array}$ & $\begin{array}{l}\text { SR, PR of } \\
\text { bladder, } \\
\text { spermatic } \\
\text { duct and } \\
\text { sigma + CT }\end{array}$ & DOD, 15 & - & + & + & + & + & + & + & - & + & + & n.an. & + \\
\hline MEITL & LAT silent & M05 & f & 85 & n.a. & SI (ileum) & n.a. & n.a. & - & + & + & $\begin{array}{l}\mathrm{n} . \\
\text { an. }\end{array}$ & + & + & + & - & - & + & + & + \\
\hline MEITL & LAT silent & M06 & $\mathrm{m}$ & 45 & $\begin{array}{l}\text { n.r. } \\
\text { CD }\end{array}$ & SI & n.a. & DOD, 5 & - & + & + & - & + & + & + & - & + & + & + & + \\
\hline MEITL & LAT silent & M07 & $\mathrm{m}$ & 59 & n.a. & $\begin{array}{l}\text { SI (jejunum, } \\
\text { ileum), LI }\end{array}$ & $\begin{array}{l}\text { SR, } \\
\text { ileocaecal } \\
\text { resection } \\
+ \text { CT }\end{array}$ & n.a. & - & + & + & + & + & + & + & - & + & + & + & + \\
\hline MEITL & LAT silent & M08 & $\mathrm{m}$ & 83 & $\begin{array}{l}\text { n.r. } \\
\text { CD }\end{array}$ & SI (jejunum) & SR & DOD, 5 & + & - & - & + & + & + & + & - & + & + & + & n.an. \\
\hline MEITL & LAT silent & M09 & $\mathrm{m}$ & 79 & $\begin{array}{l}\text { n.r. } \\
\text { CD }\end{array}$ & $\begin{array}{l}\text { SI (jejunum), } \\
\text { LI, abd. wall }\end{array}$ & $\begin{array}{l}\text { SR, left } \\
\text { hemicolectomy } \\
+ \text { steroids }\end{array}$ & n.a. & + & - & + & $\begin{array}{l}\mathrm{n} . \\
\text { an. }\end{array}$ & - & + & + & - & + & n.an. & n.an. & n.an. \\
\hline MEITL & LAT silent & M10 & f & 66 & no CD & $\begin{array}{l}\text { SI (jejunum), } \\
\text { abd. LN, } \\
\text { meningeosis } \\
\text { lymphomatosa, } \\
\text { bone marrow }\end{array}$ & $\begin{array}{l}\mathrm{SR}+\mathrm{CT}+ \\
\mathrm{PBSCT}\end{array}$ & DOD, 13 & + & - & + & $\begin{array}{l}\text { n. } \\
\text { an. }\end{array}$ & + & + & + & - & + & + & + & n.an. \\
\hline MEITL & LAT silent & M11 & $\mathrm{m}$ & 63 & $\begin{array}{l}\text { n.r. } \\
\text { CD }\end{array}$ & SI, bladder & $\begin{array}{l}\text { SR, PR of } \\
\text { bladder } \\
+ \text { CT }\end{array}$ & DOD, 31 & + & + & + & + & + & + & + & - & + & + & - & + \\
\hline MEITL & LAT silent & M12 & $\mathrm{f}$ & 48 & $\begin{array}{l}\text { n.r. } \\
\text { CD }\end{array}$ & $\begin{array}{l}\text { SI (ileum, } \\
\text { jejunum), LI, } \\
\text { abd. wall, } \\
\text { bladder, } \\
\text { pancreas, } \\
\text { subcutis }\end{array}$ & $\begin{array}{l}\text { SR + CT } \\
+ \text { PBSCT }\end{array}$ & DOD, 50 & + & n.an. & - & n.d. & + & + & + & - & - & + & + & + \\
\hline MEITL & $\begin{array}{l}\text { LAT } \\
\text { expressing }\end{array}$ & M13 & f & 52 & n.a. & SI (jejunum) & $\mathrm{SR}+\mathrm{CT}$ & DOD, 3 & - & + & + & $\begin{array}{l}\mathrm{n} . \\
\text { an. }\end{array}$ & + & + & + & + & + & + & + & + \\
\hline MEITL & $\begin{array}{l}\text { LAT } \\
\text { expressing }\end{array}$ & M14 & f & 45 & no CD & $\begin{array}{l}\text { SI (ileum), LI, } \\
\text { abd. \& retrop. } \\
\text { LN, liver, } \\
\text { bone marrow, } \\
\text { spleen }\end{array}$ & CT & n.a. & - & + & + & + & + & + & + & + & + & n.d. & n.d. & n.d. \\
\hline MEITL & $\begin{array}{l}\text { LAT } \\
\text { expressing }\end{array}$ & M15 & $\mathrm{m}$ & 55 & RS & $\begin{array}{l}\text { SI (duodenum), } \\
\text { abd. LN }\end{array}$ & $\begin{array}{l}\text { No treatment } \\
\text { possible }\end{array}$ & DOD, 1 & + & - & + & + & + & + & + & + & + & + & + & + \\
\hline
\end{tabular}


Table 1 (Continued)

\begin{tabular}{|c|c|c|c|c|c|c|c|c|c|c|c|c|c|c|c|c|c|c|c|c|}
\hline Entity & Subsets & Case & Sex & $\begin{array}{l}\text { Age } \\
\text { (years) }\end{array}$ & $\begin{array}{l}\text { Preex. } \\
C D\end{array}$ & $\begin{array}{l}\text { Site of } \\
\text { involvement }\end{array}$ & Treatment & $\begin{array}{l}\text { Outcome } \\
\text { (months) }\end{array}$ & $T C R \beta \mathrm{F} 1$ & $T C R \gamma$ & $L C K$ & $F Y N$ & $Z A P-70$ & $\begin{array}{l}\text { SYK } \\
\text { EP573Y }\end{array}$ & $\begin{array}{l}\text { SYK } \\
\text { SPM147 }\end{array}$ & $L A T$ & PLC $\gamma 1$ & $S L P-76$ & $V A V 1$ & HPK1 \\
\hline MEITL & $\begin{array}{l}\text { LAT } \\
\text { expressing }\end{array}$ & M16 & $\mathrm{m}$ & 59 & n.a. & SI (jejunum) & SR & n.a. & + & - & + & $\begin{array}{l}\mathrm{n} . \\
\text { an. }\end{array}$ & + & + & + & + & + & + & + & + \\
\hline MEITL & $\begin{array}{l}\text { LAT } \\
\text { expressing }\end{array}$ & M17 & $\mathrm{m}$ & 68 & $\begin{array}{l}\text { n.r. } \\
\text { CD }\end{array}$ & SI (ileum) & SR & n.a. & + & - & + & + & - & + & + & + & + & + & + & - \\
\hline MEITL & $\begin{array}{l}\text { LAT } \\
\text { expressing }\end{array}$ & M18 & $\mathrm{m}$ & 52 & n.a. & $\begin{array}{l}\text { SI (duodenum), } \\
\text { gallbladder }\end{array}$ & SR & n.a. & + & - & + & n.d. & + & + & + & + & n.d. & n.d. & n.d. & n.d. \\
\hline MEITL & $\begin{array}{l}\text { Non- } \\
\text { classifiable }\end{array}$ & M19 & $\mathrm{m}$ & 73 & RS & SI (jejunum) & $\begin{array}{l}\text { SR + CT + } \\
\text { PBSCT }\end{array}$ & DOD, 10 & - & + & + & $\begin{array}{l}\mathrm{n} . \\
\text { an. }\end{array}$ & + & + & + & n.an. & + & + & + & + \\
\hline MEITL & $\begin{array}{l}\text { Non- } \\
\text { classifiable }\end{array}$ & M20 & $\mathrm{f}$ & 64 & $\begin{array}{l}\text { n.r. } \\
\text { CD }\end{array}$ & $\begin{array}{l}\text { SI (jejunum, } \\
\text { ileum) appendix }\end{array}$ & SR & DOD, 1 & - & + & - & $\begin{array}{l}\mathrm{n} . \\
\text { an. }\end{array}$ & + & + & + & n.an. & - & + & + & + \\
\hline EATL & & E01 & $\mathrm{m}$ & 79 & n.a. & SI & SR & DOD, 0 & - & - & + & n.d. & + & - & - & - & n.d. & n.d. & n.d. & n.d. \\
\hline EATL & & E02 & $\mathrm{m}$ & 58 & $\mathrm{CD}$ & SI (ileum), LI & $\begin{array}{l}\text { SR, } \\
\text { ileocaecal } \\
\text { resection } \\
+ \text { CT }\end{array}$ & n.a. & - & - & + & + & + & - & - & - & + & n.d. & n.d. & n.d. \\
\hline EATL & & E03 & $\mathrm{m}$ & 80 & n.a. & SI (jejunum) & SR & n.a. & - & - & - & $\begin{array}{l}\mathrm{n} . \\
\text { an. }\end{array}$ & + & - & - & - & + & - & - & + \\
\hline EATL & & E04 & $\mathrm{m}$ & 51 & CD & $\begin{array}{l}\text { SI (jejunum, } \\
\text { ileum) }\end{array}$ & $\mathrm{SR}+\mathrm{CT}$ & DOD, 80 & - & - & + & + & + & - & - & - & - & + & + & + \\
\hline EATL & & E05 & $\mathrm{m}$ & 44 & CD & $\begin{array}{l}\text { SI (jejunum, } \\
\text { ileum), abd. } \\
\text { LN, lung }\end{array}$ & $\mathrm{SR}+\mathrm{CT}$ & DOD, 7 & - & - & + & + & + & - & - & - & + & n.d. & n.d. & n.d. \\
\hline EATL & & E06 & $\mathrm{m}$ & 65 & n.a. & SI, abd. LN & SR & DOD, 0.5 & - & - & - & + & - & - & - & - & - & - & - & + \\
\hline EATL & & E07 & $\mathrm{m}$ & 79 & $\mathrm{CD}$ & $\begin{array}{l}\text { SI (jejunum, } \\
\text { ileum) }\end{array}$ & SR & n.a. & - & - & + & - & + & - & - & - & + & + & + & + \\
\hline EATL & & E08 & f & 65 & $\mathrm{CD}$ & SI & n.a. & n.a. & - & - & - & $\begin{array}{l}\mathrm{n} . \\
\text { an. }\end{array}$ & + & - & - & - & - & + & - & + \\
\hline EATL & & E09 & $\mathrm{m}$ & 61 & CD & $\begin{array}{l}\text { SI (jejunum), } \\
\text { abd. and } \\
\text { retrop. LN }\end{array}$ & SR & n.a. & + & - & + & $\begin{array}{l}\text { n. } \\
\text { an. }\end{array}$ & + & - & - & - & - & + & + & + \\
\hline EATL & & E10 & $\mathrm{m}$ & 59 & CD & SI (ileum) & SR & n.a. & + & + & + & + & + & - & - & - & + & + & + & + \\
\hline EATL & & E11 & $\mathrm{f}$ & 84 & CD & SI (jejunum) & SR & n.a. & - & - & + & + & + & - & - & + & + & + & + & + \\
\hline EATL & & E12 & $\mathrm{m}$ & 72 & CD & SI & n.a. & n.a. & - & + & + & $\begin{array}{l}\text { n. } \\
\text { an. }\end{array}$ & + & - & - & + & + & n.d. & n.d. & n.d. \\
\hline EATL & & E13 & $\mathrm{m}$ & 72 & CD & SI, LI, stomach & n.a. & n.a. & - & - & n.d. & n.d. & + & - & - & n.d. & n.d. & n.d. & n.d. & n.d. \\
\hline EATL & & E14 & $\mathrm{f}$ & 51 & CD & SI & SR & n.a. & n.an. & n.an. & - & - & + & - & - & n.an. & n.an. & n.d. & n.d. & n.d. \\
\hline
\end{tabular}

Abbreviations: abd., abdominal; CD, celiac disease; DOD, died of disease; CT, chemotherapy; LI, large intestine; LN, lymph nodes; n.a., information not available; n.an., not analyzable; n.d., not done due to limited material; n.r., no record of associated symptoms of; PBSCT, peripheral blood stem cell transplantation; PR, partial resection; preex., preexisting; retrop., retroperitoneal; RS, refractory sprue; SI, small intestine; SR, segment resection of the intestine. 


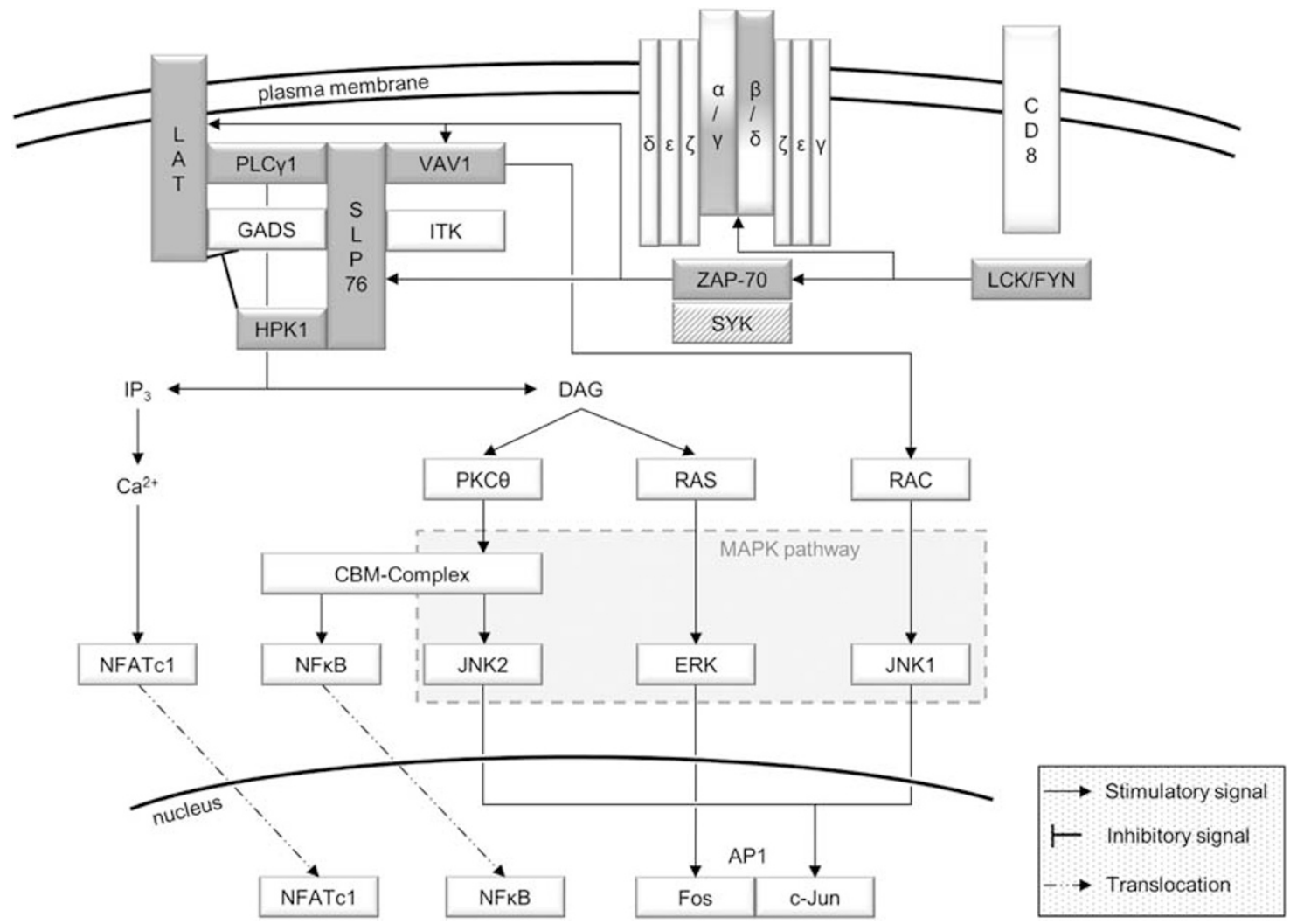

Figure 1 Schematic overview of the TCR signaling cascade. Molecules which are immunohistochemically investigated and discussed are highlighted in gray. Notably, the functional role of SYK in MEITL is still under investigation.

South Brisbane, Qld, Australia). Only bidirectional mutations were scored.

\section{Methylation Analysis}

A DNA methylation analysis of a $137 \mathrm{bp}$ region within the SYK promoter, containing $4 \mathrm{CpG}$ sites, was performed by bisulfite pyrosequencing using the predesigned Hs_SYK_01_PM PyroMark CpG Assay (Qiagen, Hilden Germany). All other kits, reagents, devices and the software were also purchased from Qiagen and used according to the manufacturer's instructions. Genomic DNA was sodium bisulfite modified with the EpiTect Fast DNA Bisulfite Kit. The SYK promoter region of interest was amplified by PCR using the PyroMark PCR Kit and primers supplied in the Hs_SYK_01_PM PyroMark CpG Assay. The PCR products were visualized by $2 \%$ agarose gel electrophoresis. A single-stranded DNA was prepared from the PCR product with the PyroMark Q24 Vacuum Workstation and then sequenced with primers provided in the Hs_SYK_01_PM PyroMark CpG Assay and PyroMark Gold Q24 Reagents on the PyroMark Q24 sequencer. The percent methylation of the CpG sites of interest was calculated using the PyroMark Q24 software. According to the manufacturer, generated data are considered as valid if the obtained value of the $100 \%$ control is not less than $80 \%$ and of the $0 \%$ control not more than $10 \%$, respectively. A CpG site was assessed as methylated if the calculated percentage of methylation was greater than $10 \%$ and at least $5 \%$ above the $0 \%$ control. Otherwise, the $\mathrm{CpG}$ site was ranked as hypomethylated.

\section{Statistics}

The statistical inference was performed using the binomial test which is an exact hypothesis test. The calculations of the $P$-values of the various null hypotheses (Supplementary Table 7) were performed with R Statistical Software Package, available from http://www.r-project.org, and validated with SPSS Statistics software (IBM, Ehningen, Germany). $P$-values $<0.05$ were considered statistically significant and $P$-values $<0.01$ were considered statistically highly significant.

\section{Results}

\section{Immunohistochemical Analysis of the TCR}

We analyzed the expression of the TCR (TCR $\beta$-chain and TCR $\gamma$-chain) in our extended study set (Supplementary Table 1; Figure 2 and 3).

In MEITL, a positive TCR phenotype is frequent $(P<0.05$, Supplementary Table 7$)$ which was in our study made up of a immunoreactivity for the TCR $\gamma$ antibody $(18 / 40)$ corresponding to a $\gamma \delta$-TCR phenotype, followed by an expression of the TCR $\beta$ antibody (10/40) corresponding to an $\alpha \beta$-TCR phenotype 
and rarely a positivity of both TCR chains (1/40) corresponding to a dual TCR expression. Only some cases (4/40) displayed a TCR silent phenotype characterized by a loss of expression of both TCR chains. The remaining cases (7/40) were not eligible for analysis because one of the two TCR chain antibodies was not evaluable.

In EATL, a common feature is a TCR silent phenotype $(P<0.05$, Supplementary Table 7$)$ which was in our study represented by the majority of cases (17/27). A positive TCR phenotype was infrequently found with the most common expression of the $\alpha \beta$ TCR (5/27), followed by the expression of the $\gamma \delta$-TCR (3/27) and a dual TCR expression (1/27). In one case both TCR chain antibodies were not analyzable due to technical reasons.

Taken together, a positive TCR expression, containing both an $\alpha \beta$ - and a $\gamma \delta$-T-cell deriving subset, is frequent in MEITL and a TCR silent phenotype is common in EATL.

\section{Immunohistochemical Analysis of SYK and ZAP-70}

We examined the expression of SYK and ZAP-70 in all cases of our extended study set (Supplementary Table 1; Figures 2 and 3). We found a most striking difference $(P<0.01$, Supplementary Table 7$)$ in the expression of SYK between MEITL and EATL which was fully validated with a second antibody against SYK in our core study set.

Focusing on MEITL, nearly all cases displayed a strong cytoplasmic expression of SYK $(38 / 40)$ and ZAP-70 (37/40) in all neoplastic cells thereby showing a coexpression in most cases (35/40). In few cases we detected a loss of ZAP-70 resulting in an exclusive expression of SYK (2/40), or a lacking coexpression of SYK leading to an exclusive expression of ZAP-70 (2/40). In one case the examination of ZAP-70 failed due to technical reasons.

In EATL, all cases exhibited a consistent negativity of SYK (0/27) in all neoplastic cells, whereas ZAP-70 (26/27) showed a marked positivity in the vast majority of these cases. One case displayed a loss of ZAP-70 along with a TCR silent phenotype.

\section{Amplicon Deep Sequencing Analysis of SYK, DNMT3A, IDH2, and TET2}

We performed amplicon deep sequencing of $S Y K$ including all coding exons as well as a part of the promoter region containing various motifs for several transcription factors. ${ }^{18}$ Additionally, we screened already reported mutations within the DNA methyltransferase $3 \alpha(D N M T 3 A)$ gene, ${ }^{19}$ the isocitrate dehydrogenase 2 (IDH2) gene ${ }^{20}$ and the ten-eleventranslocation 2 (TET2) gene $^{21,22}$ focusing on their occurrence in MEITL and EATL. The exact position of each amplicon is given in Supplementary Table 4. 48 samples were sequenced in four 12-plex runs ${ }^{23}$ obtaining an average of 128322 high-quality sequencing reads corresponding to a mean of $50.74 \%$ of the total reads (Supplementary Table 8). The mean coverage per amplicon was 227-fold (Supplementary Figure 1). For analysis, we selected a total of 36 samples including 34 lymphomas $\left(n_{\text {MEITL }}=20\right.$, $\left.n_{\text {EATL }}=14\right)$ as well as the two multiple myeloma cell lines KMS12BM and JJN3, which served as internal controls (Supplementary Table 5).

A total of 741 nonsynonymous variants passed the filter setting and were grouped as follows:

Variants $n=1$ : The majority of these variants (683/741) were only found in one sample (Supplementary Figure 2) and not further analyzed.

Variants $n \geq 2$ : The remaining variants (58/741) were found in at least two samples $(n \geq 2)$.

These variants were classified into the following three sets: (a) Potentially relevant mutations $n \geq 2$ : This set contained a total of 24 variants (Supplementary Table 5; Supplementary Figure 2) which were predominantly detected in the MEITL cases $(23 / 24)$. In MEITL, most variants (18/23) were predicted to be pathogenic by at least one of the two functional scores, PolyPhen or SIFT. Only one of these variants, SYK p. V385A, was simultaneously detected in three samples while the remaining variants were displayed in two cases (Supplementary Table 9; Supplementary Figure 2A) comprising a mean variant allele frequency of $11 \%$ for $S Y K, 23 \%$ for the $S Y K$ promoter, $10 \%$ for DNMT3A, $10 \%$ for $I D H 2$ and $13 \%$ for TET2, respectively. Considering EATL, only one variant (1/24), the TET2 p.E1411K, was found in two cases with a mean variant allele frequency of $8 \%$. All other genes invariably exhibited one sample per variant (Supplementary Table 9; Supplementary Figure 2B). Therefore our data exclude a hotspot mutation $(\geq 45 \%$ of cases; Supplementary Table 7) in both, MEITL and EATL, within $S Y K$, the $S Y K$ promoter, DNMT3A, IDH2, and TET2 as investigated here.

(b) SNP $n \geq 2$ : This set comprised six variants classified as SNPs (Supplementary Table 5).

(c) Technical errors $n \geq 2$ : A total of 26 homopolymer associated insertions/deletions, ${ }^{24}$ a known shortcoming of the 454 sequencing technology, ${ }^{25}$ and two substitution errors were identified using the internal controls as well as a random check with sanger sequencing (Supplementary Tables 5 and 6).

\section{Methylation Analysis of the SYK Promoter}

We studied the methylation status within the $S Y K$ promoter in a random selection of six MEITL and seven EATL samples from our extended study set. Three CpG sites displayed a clear-cut distinction $(P<0.05$, Supplementary Table 7$)$ of the methylation status between MEITL and EATL (Figure 4). Although reflecting the results of the other three CpGs, the fourth CpG site was unfortunately technically invalid (Supplementary Table 10). The six MEITL cases displayed a methylation of 1 to $4 \%$ (mean methylation $3 \%$ ) and alternated closely around the $0 \%$ control. The seven EATL cases showed a methylation 


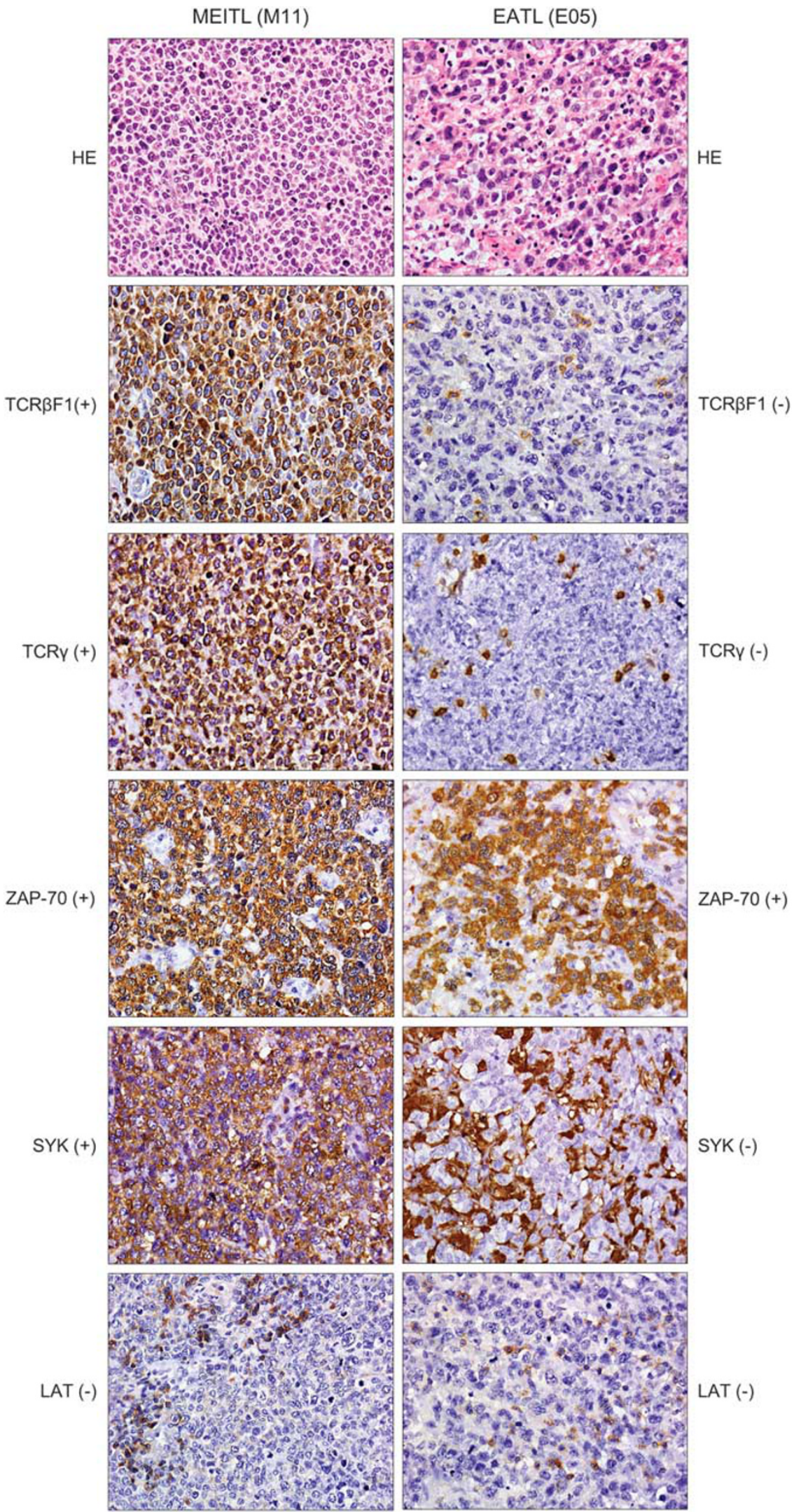

Figure 2 A characteristic hematoxylin and eosin (HE) stain as well as immunostainings of the two TCR chains, ZAP-70, SYK, and LAT of a MEITL case and an EATL case including their scoring results (positive or negative). 
a

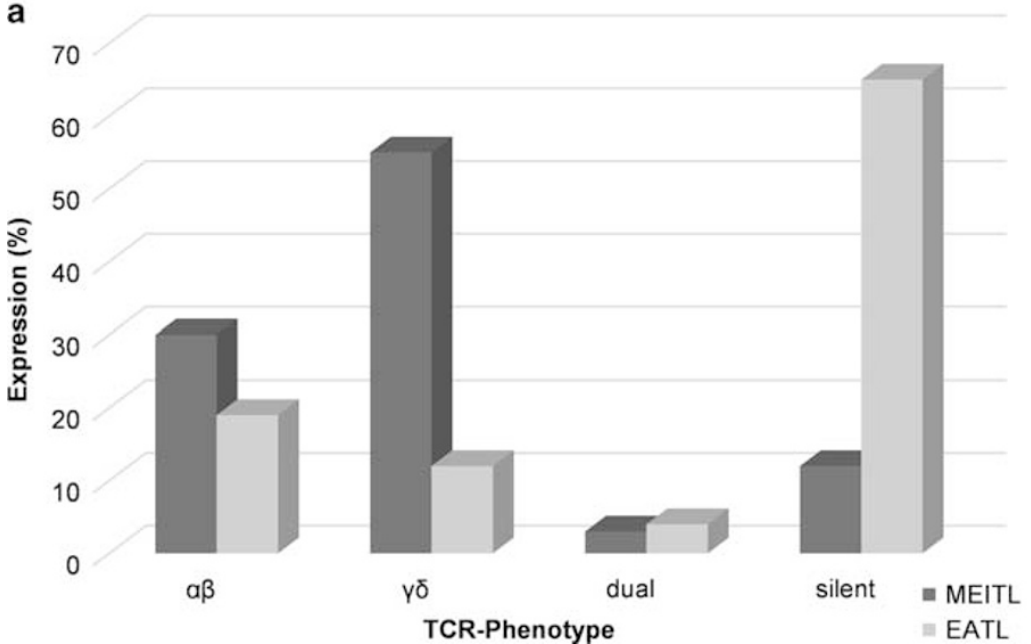

b

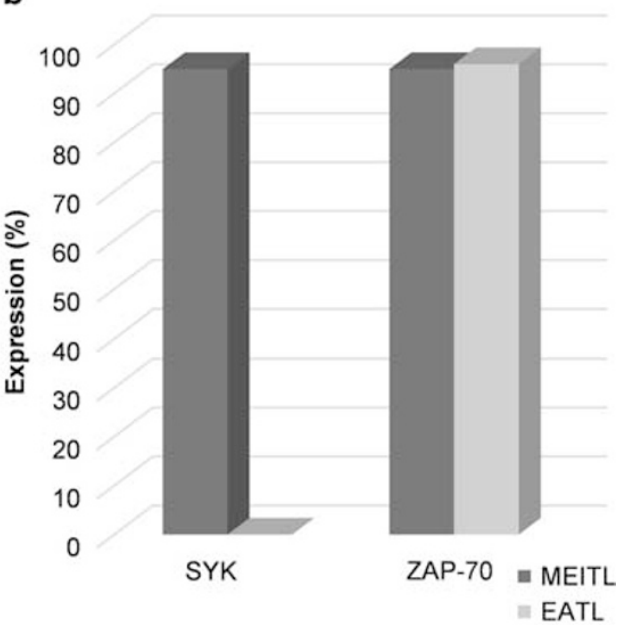

Figure 3 Immunohistochemical expression of the TCR phenotypes (a) as well as SYK and ZAP-70 (b) in MEITL and EATL distributed by percentage.

ranging from $17 \%$ to $84 \%$ (mean methylation $41 \%$ ). In spite of the great variance this result exhibits a marked difference to the methylation level of the MEITL cases and the $0 \%$ control.

In summary, a distinct pathophysiological expression of SYK is a characteristic feature of MEITL, probably due to a hypomethylation of its promoter site. On the contrary, SYK is generally negative in EATL. Furthermore, on the DNA level neither MEITL nor EATL display a hotspot mutation within $S Y K$, as well as in the analyzed regions of the $S Y K$ promoter, DNMT3A, IDH2, and TET2.

\section{Immunohistochemical Analysis of TCR Signal Priming}

In our core study set we examined LCK and FYN (Figure 1, Table 1). ${ }^{26,27}$ In MEITL, almost all cases with a positive TCR phenotype expressed at least one of the kinases as far as the stains could be assessed (LCK: 15/17; FYN: 8/17). In the two MEITL cases showing a TCR silent phenotype, FYN was completely negative, while LCK was absent in one case. Focusing on EATL, both kinases predominantly exhibited a positivity (LCK: 9/14; FYN: 6/14) in all analyzable stains including the three cases with a positive TCR expression.

\section{Immunohistochemical Analysis of the LAT-SLP-76 Signaling Hub and LAT Subsets}

In our core study set we analyzed LAT, PLC $\gamma 1$, SLP-76, Vav1, and HPK1 participating in the LAT-SLP-76 signaling hub (Figure 1; Table 1). ${ }^{28-33}$

In MEITL, two subsets could be discriminated by the detection of LAT $(P<0.05$; Supplementary Table 7). The LAT expressing subset (6/20) constantly exhibited a positive TCR phenotype. The LAT silent subset (12/20) featured a positive TCR phenotype in most cases (9/12). Interestingly, in both subsets a coexpression of PLC $\gamma 1$, SLP-76, Vav1, and HPK1 were predominantly detected (Supplementary

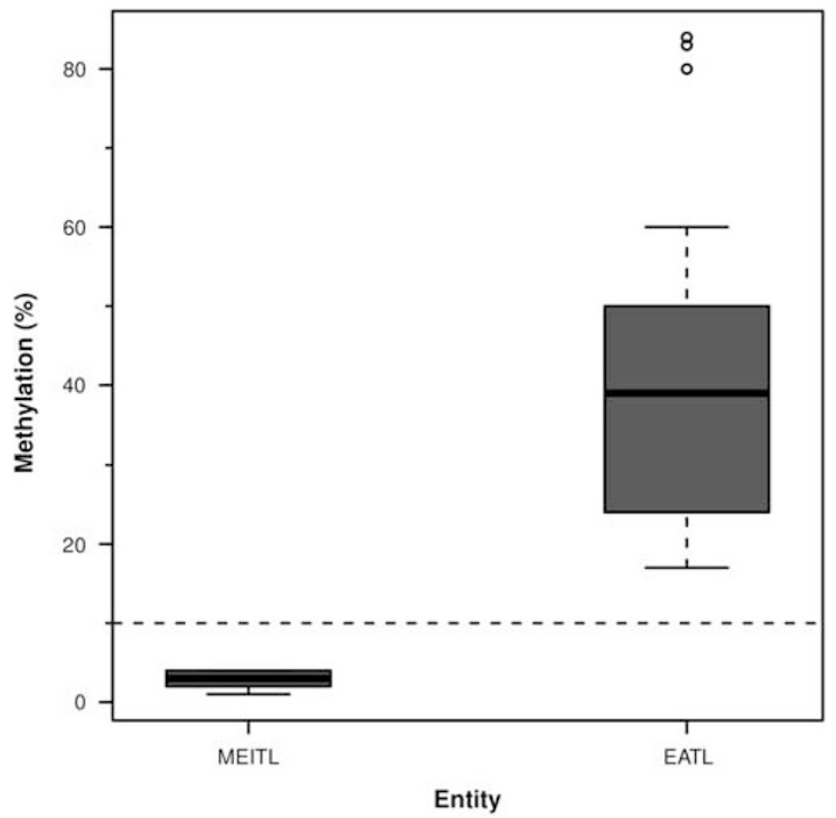

Figure 4 Methylation status of the SYK promoter in MEITL and EATL. This box- and whisker-plot shows the distribution of the methylation per entity. The dotted line marks the cut off between methylation and hypomethylation.

Table 11). In the remaining two cases LAT could not be evaluated due to technical reasons.

Unlike MEITL, there were no substantial subsets in EATL. A positivity of LAT was infrequent (2/14). The characteristic feature was a complete negativity of LAT (10/14) corresponding to a TCR silent phenotype in most of them (8/14). PLC $\gamma 1$, SLP-76, Vav1, and HPK1 were commonly expressed (Supplementary Table 11). In two cases, LAT could not be examined due to technical reasons.

\section{Clinical Correlation with Respect to the LAT Subsets}

The entire group of MEITL patients was composed of 13 men and 7 women (male to female ratio 2:1) with 
an age distribution from 45 to 85 years resulting in a mean age of 62 years. Only two patients $(2 / 20)$ had a history of refractory sprue, while the remaining patients with an available record $(13 / 20)$ had no celiac disease associated symptoms although only two of them were actually tested negative.

In view of the immunohistochemically defined LAT subsets the distribution of sex, age, and outcome was as follows. The LAT expressing subset (6 cases) contained 4 men and 2 women with a mean age of 55 years (45-68 years; Figure 5; Table 1). Unfortunately, the data on outcome were limited $(2 / 6)$. However, these patients died of disease 1 and 3 months after diagnosis, respectively. The LAT silent subset (12 cases) was composed of 8 men and 4 women with a mean age of 65 years (45-85 years; Figure 5; Table 1). As far as the data on outcome were available, the patients $(8 / 12)$ died of disease between 5 and 50 months after diagnosis corresponding to a mean survival of 19 months.

The EATL group of patients consisted of 11 men and 3 women (male to female ratio 4:1) expressing a mean age of 66 years (44-84 years; Figure 5; Table 1). All patients with available data had a history of celiac disease (11/14). Although the data on outcome were limited (4/14), there was a considerable variation ranging from immediate death to a survival of 80 months after diagnosis. For each lymphoma entity, the site of involvement as well as the treatment are summarized in Table 1.

Taken together, MEITL is divided into a LAT expressing and a LAT silent subset. Specifically, in our study LAT-positive MEITL patients presented an earlier onset of the disease and, potentially, a more aggressive clinical course. On the contrary, the commonly TCR silent EATL cases were

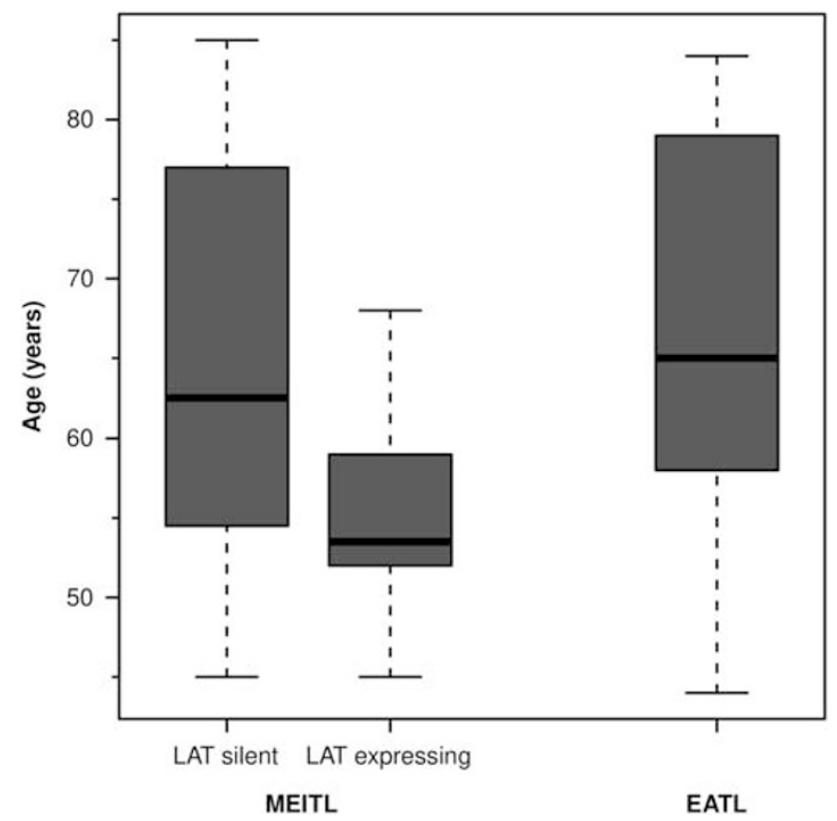

Figure 5 Age distribution in MEITL based on the LAT defined subsets and EATL. characterized by a loss of LAT. Both lymphomas usually displayed a positivity of molecules involved in the proximal TCR signaling (LCK, FYN, SLP-76, VAV1, HPK1, PLC $\gamma 1$ ) even in TCR silent phenotypes.

\section{Discussion}

Our study further substantiates the categorization of MEITL as a distinct entity. ${ }^{2}$ Importantly, the composition of the TCR itself appears to differ between MEITL and EATL. A substantial body of evidence suggests a $\gamma \delta$-TCR expression as a common feature of MEITL. ${ }^{4,6,7,9,15}$ Since an $\alpha \beta$-TCR negative subset most likely contains a fraction of cases with $\gamma \delta$-T-cell origin, ${ }^{34}$ the common $\gamma \delta$-TCR phenotype in MEITL is further underpinned by several TCR $\beta$-chain focused studies ${ }^{8,35,36}$ exhibiting an $\alpha \beta$-TCR negative subset. In our study, we most frequently detected a $\gamma \delta$ TCR expression in the analyzable MEITL cases (18/33) as well, followed by an $\alpha \beta$-TCR expression (10/33), less commonly a TCR silent phenotype (4/33) and a dual TCR expression (1/33). Hence, our data are in accordance with the current view of a positive TCR expression, containing both an $\alpha \beta$ - and a $\gamma \delta$-derivation, in MEITL. With regard to the TCR expression itself, we found a positive TCR expression in most MEITL cases (29/33), while no TCR was displayed in the majority of the EATL cases (17/26). Thus, the expression of the TCR is an indicator, though no discriminator, differentiating between MEITL and EATL with statistical significance. ${ }^{37}$ In addition, our study adds to the notion that the loss of TCR expression is common in EATL. ${ }^{34,38}$

As a main finding in our study, SYK is strongly expressed in the vast majority of MEITL cases. It is a non-receptor type protein tyrosine kinase which is structurally and functionally related to ZAP-70 and under physiological conditions usually not expressed in mature T-cells. ${ }^{39}$ SYK has already been a subject of investigation in T-cell lymphoma research, ${ }^{40-48}$ although it has not been studied extensively in MEITL and EATL to date. ${ }^{12,49}$ We here show a marked cytoplasmic expression of SYK in almost all MEITL cases (38/40), while the EATL cases displayed a consistent negativity for SYK $(0 / 27)$. Thus, the immunohistochemical SYK expression serves as a distinctive marker between MEITL and EATL in the diagnostic setting with high statistical significance. Whether SYK expression actively influences TCR signaling in MEITL and whether SYK might therefore serve as a potential target for therapy, e.g. using SYK inhibitors, remains to be investigated further.

In search of the cause of the marked SYK overexpression in MEITL we performed a methylation analysis of the $S Y K$ promoter. Even though the study set was limited (six MEITL and seven EATL cases), our data show an unambiguous result. All MEITL cases showed a hypomethylation of the SYK promoter while all EATL samples were methylated strongly arguing that hypomethylation of the $S Y K$ promoter 
in MEITL abrogates the physiological SYK-negativity in the tumor cells. In contrast, genetic mutations in $S Y K$ or its promoter are less likely responsible for the SYK upregulation in MEITL, since our amplicon deep sequencing revealed no $S Y K$ mutations in more than three cases. We also searched for mutations within DNMT3A, ${ }^{19} \mathrm{IDH} 2,{ }^{20}$ and TET2 $2^{21,22}$ known to be present in other T-cell lymphomas. As a result, we can significantly substantiate the view that mutations in these genes only play a minor role in the pathogenesis of MEITL and EATL, if at all. ${ }^{11,14,15}$

Since SYK expression might perturb TCR signal transduction, ${ }^{50}$ we studied the expression of some key molecules of the proximal TCR signaling cascade. In MEITL, we detected an almost consistent expression of the TCR complex and most of the investigated molecules participating in the TCR signaling cascade (LCK, FYN, ZAP-70, PLC $\gamma 1$, SLP-76, VAV1, HPK1). One exception was LAT, which represents the main hub of the proximal TCR signal transduction. ${ }^{28,51}$ Only one third of the MEITL cases displayed a positivity of LAT (6/18), while the majority of the MEITL cases showed a negativity of LAT (12/18). Furthermore, LAT expressing MEITL patients were on average ten years younger compared to the remainder. Hence, MEITL shows both a LAT expressing and a LAT silent subset with statistical significance which, at least in our study, displayed a varying disease onset. Due to the role of LAT within the proximal TCR signal transduction, one could speculate that an enhanced TCR signaling caused by the presence of $\mathrm{SYK}^{50}$ is more effective in the LAT expressing subset than in the LAT silent subset ${ }^{52-55}$ resulting in an earlier onset of disease and probably a more aggressive course of this subtype overall. This condition seems to parallel the situation in the subset of B-cell chronic lymphocytic leukemia featuring unmutated immunoglobulin heavy chain variable gene segments, in which BCR signaling is increased due to the expression of ZAP-70 $0^{56,57}$ most likely forming a strong risk factor. ${ }^{58}$

On the contrary, EATL displayed a constant negativity for SYK and predominantly a TCR silent phenotype. The studied molecules involved in the proximal TCR signal transduction (LCK, FYN, ZAP-70, PLC $\gamma 1$, SLP-76, VAV1, HPK1) were usually expressed except for LAT. A loss of LAT was detected in the majority of the analyzable cases (10/12) mainly matching the lacking TCR expression. The finding that LAT expression mirrors TCR expression is well in line with previous reports in anaplastic large cell lymphoma by us ${ }^{48}$ and others. ${ }^{59}$

In conclusion, an $\alpha \beta$ - and a $\gamma \delta$-TCR phenotype is a common feature of MEITL and SYK expression emerges as another distinctive diagnostic marker in MEITL besides CD56 and megakaryocyte-associated tyrosine kinase. Whether SYK expression actively influences TCR signaling in MEITL and whether SYK might therefore serve as a potential druggable target needs to be addressed in future studies.

\section{Acknowledgments}

We thank Theodora Nedeva and Tina Grieb for excellent technical assistance. Furthermore, we thank Elisa Bach for her excellent technical support and service on the Fluidigm Access Array Platform.

\section{Disclosure/conflict of interest}

The authors declare no conflict of interest.

\section{References}

1 Chott A, Haedicke W, Mosberger I, et al. Most CD56+ intestinal lymphomas are CD8+CD5-T-cell lymphomas of monomorphic small to medium size histology. Am J Pathol 1998;153:1483-1490.

2 Swerdlow SH, Campo E, Pileri SA, et al. The 2016 revision of the World Health Organization classification of lymphoid neoplasms. Blood 2016;127:2375-2390.

3 Chott A, Vesely M, Simonitsch I, et al. Classification of intestinal T-cell neoplasms and their differential diagnosis. Am J Clin Pathol 1999;111:S68-S74.

4 Chan JK, Chan AC, Cheuk W, et al. Type II enteropathyassociated T-cell lymphoma: a distinct aggressive lymphoma with frequent $\gamma \delta \mathrm{T}$-cell receptor expression. Am J Surg Pathol 2011;35:1557-1569.

5 Tan SY, Ooi AS, Ang MK, et al. Nuclear expression of MATK is a novel marker of type II enteropathy-associated T-cell lymphoma. Leukemia 2011;25:555-557.

6 Tan SY, Chuang SS, Tang T, et al. Type II EATL (epitheliotropic intestinal T-cell lymphoma): a neoplasm of intra-epithelial T-cells with predominant CD8 $\alpha \alpha$ phenotype. Leukemia 2013;27:1688-1696.

7 Tse E, Gill H, Loong F, et al. Type II enteropathyassociated T-cell lymphoma: a multicenter analysis from the Asia Lymphoma Study Group. Am J Hematol 2012;87:663-668.

8 Takeshita M, Nakamura S, Kikuma K, et al. Pathological and immunohistological findings and genetic aberrations of intestinal enteropathy-associated $\mathrm{T}$ cell lymphoma in Japan. Histopathology 2011;58:395-407.

9 Tomita S, Kikuti YY, Carreras J, et al. Genomic and immunohistochemical profiles of enteropathyassociated T-cell lymphoma in Japan. Mod Pathol 2015;28:1286-1296.

10 Deleeuw RJ, Zettl A, Klinker E, et al. Whole-genome analysis and HLA genotyping of enteropathy-type T-cell lymphoma reveals 2 distinct lymphoma subtypes. Gastroenterology 2007;132:1902-1911.

11 Roberti A, Dobay MP, Bisig B, et al. Type II enteropathy-associated T-cell lymphoma features a unique genomic profile with highly recurrent SETD2 alterations. Nat Commun 2016;7:12602.

12 Moffitt AB, Ondrejka SL, McKinney $\mathrm{M}$, et al. Enteropathy-associated T cell lymphoma subtypes are characterized by loss of function of SETD2. J Exp Med 2017;214:1371-1386.

13 Küçük C, Jiang B, Hu X, et al. Activating mutations of STAT5B and STAT3 in lymphomas derived from $\gamma \delta$-T or NK cells. Nat Commun 2015;6:6025.

14 Nairismägi ML, Tan J, Lim JQ, et al. JAK-STAT and G-protein-coupled receptor signaling pathways are frequently altered in epitheliotropic intestinal T-cell lymphoma. Leukemia 2016;30:1311-1319. 
15 Nicolae A, Xi L, Pham TH, et al. Mutations in the JAK/ STAT and RAS signaling pathways are common in intestinal T-cell lymphomas. Leukemia 2016;30: 2245-2247.

16 Isaacson PG, Chott A, Ott G, et al. Enteropathyassociated T-cell lymphoma. In: Swerdlow SH, Campo $\mathrm{E}$, Harris NL, et al. editors. WHO Classification of Tumours of Haematopoietic and Lymphoid Tissues. 4th ed. Lyon, France: IARC, 2008, p 289-291.

17 Weißbach S, Langer C, Puppe B, et al. The molecular spectrum and clinical impact of DIS3 mutations in multiple myeloma. Br J Haematol 2015;169:57-70.

18 Ghosh D, Kis-Toth K, Juang YT, et al. CREMo suppresses spleen tyrosine kinase expression in normal but not systemic lupus erythematosus T cells. Arthritis Rheum 2012;64:799-807.

19 Couronné L, Bastard C, Bernard OA. TET2 and DNMT3A mutations in human T-cell lymphoma. N Engl J Med 2012;366:95-96.

20 Cairns RA, Iqbal J, Lemonnier F, et al. IDH2 mutations are frequent in angioimmunoblastic T-cell lymphoma. Blood 2012;119:1901-1903.

21 Lemonnier F, Couronné L, Parrens M, et al. Recurrent TET2 mutations in peripheral T-cell lymphomas correlate with TFH-like features and adverse clinical parameters. Blood 2012;120:1466-1469.

22 Quivoron C, Couronné L, Della Valle V, et al. TET2 inactivation results in pleiotropic hematopoietic abnormalities in mouse and is a recurrent event during human lymphomagenesis. Cancer Cell 2011;20: 25-38.

23 Mutzbauer G, Maurus K, Buszello C, et al. SYK expression in MEITL - NGS data set. European Genome-phenome Archive http://www.ebi.ac.uk/ega/ accession number: EGAS00001002435 (2017).

24 Luo C, Tsementzi D, Kyrpides N, et al. Direct comparisons of Illumina vs. Roche 454 sequencing technologies on the same microbial community DNA sample. PLoS One 2012;7:e30087.

25 Raca G, Jackson C, Warman B, et al. Next generation sequencing in research and diagnostics of ocular birth defects. Mol Genet Metab 2010;100:184-192.

26 Acuto O, Di Bartolo V, Michel F. Tailoring T-cell receptor signals by proximal negative feedback mechanisms. Nat Rev Immunol 2008;8:699-712.

27 Wang H, Kadlecek TA, Au-Yeung BB, et al. ZAP-70: an essential kinase in T-cell signaling. Cold Spring Harb Perspect Biol 2010;2:a002279.

28 Balagopalan L, Coussens NP, Sherman E, et al. The LAT story: a tale of cooperativity, coordination, and choreography. Cold Spring Harb Perspect Biol 2010;2: a005512.

29 Koretzky GA, Abtahian F, Silverman MA. SLP76 and SLP65: complex regulation of signalling in lymphocytes and beyond. Nat Rev Immunol 2006;6:67-78.

30 Ksionda O, Saveliev A, Köchl R, et al. Mechanism and function of Vav1 localisation in TCR signalling. J Cell Sci 2012;125:5302-5314.

31 Devkota S, Joseph RE, Min L, et al. Scaffold protein SLP-76 primes PLCy1 for activation by ITK-mediated phosphorylation. J Mol Biol 2015;427:2734-2747.

32 Coussens NP, Hayashi R, Brown PH, et al. Multipoint binding of the SLP-76 SH2 domain to ADAP is critical for oligomerization of SLP-76 signaling complexes in stimulated T cells. Mol Cell Biol 2013;33:4140-4151.

33 Lasserre R, Cuche C, Blecher-Gonen R, et al. Release of serine/threonine-phosphorylated adaptors from signaling microclusters down-regulates $\mathrm{T}$ cell activation. J Cell Biol 2011;195:839-853.

34 Garcia-Herrera A, Song JY, Chuang SS, et al. Nonhepatosplenic $\gamma \delta$ T-cell lymphomas represent a spectrum of aggressive cytotoxic T-cell lymphomas with a mainly extranodal presentation. Am J Surg Pathol 2011;35:1214-1225.

35 Chuang SS, Chang ST, Chuang WY, et al. NK-cell lineage predicts poor survival in primary intestinal NKcell and T-cell lymphomas. Am J Surg Pathol 2009;33: 1230-1240.

36 Sun J, Lu Z, Yang D, et al. Primary intestinal T-cell and NK-cell lymphomas: a clinicopathological and molecular study from China focused on type II enteropathyassociated T-cell lymphoma and primary intestinal NKcell lymphoma. Mod Pathol 2011;24:983-992.

37 Wilson AL, Swerdlow SH, Przybylski GK, et al. Intestinal $\gamma \delta$ T-cell lymphomas are most frequently of type II enteropathy-associated T-cell type. Hum Pathol 2013;44:1131-1145.

38 Tjon JM, Verbeek WH, Kooy-Winkelaar YM, et al. Defective synthesis or association of T-cell receptor chains underlies loss of surface T-cell receptor-CD3 expression in enteropathy-associated T-cell lymphoma. Blood 2008;112:5103-5110.

39 Chu DH, Spits H, Peyron JF, et al. The Syk protein tyrosine kinase can function independently of CD45 or Lck in $\mathrm{T}$ cell antigen receptor signaling. EMBO J 1996;15:6251-6261.

40 Weil R, Levraud JP, Dodon MD, et al. Altered expression of tyrosine kinases of the Src and Syk families in human T-cell leukemia virus type 1-infected T-cell lines. J Virol 1999;73:3709-3717.

41 Thompson MA, Stumph J, Henrickson SE, et al. Differential gene expression in anaplastic lymphoma kinase-positive and anaplastic lymphoma kinasenegative anaplastic large cell lymphomas. Hum Pathol 2005;36:494-504.

42 Pozzobon M, Marafioti T, Hansmann ML, et al. Intracellular signalling molecules as immunohistochemical markers of normal and neoplastic human leucocytes in routine biopsy samples. Br J Haematol 2004;124:519-533.

43 Streubel B, Vinatzer U, Willheim M, et al. Novel t(5;9) (q33;q22) fuses ITK to SYK in unspecified peripheral T-cell lymphoma. Leukemia 2006;20:313-318.

44 Pechloff K, Holch J, Ferch U, et al. The fusion kinase ITK-SYK mimics a $\mathrm{T}$ cell receptor signal and drives oncogenesis in conditional mouse models of peripheral T cell lymphoma. J Exp Med 2010;207: 1031-1044.

45 Dierks C, Adrian F, Fisch P, et al. The ITK-SYK fusion oncogene induces a T-cell lymphoproliferative disease in mice mimicking human disease. Cancer Res 2010;70: 6193-6204.

46 Ortiz S, Lee W, Smith D, et al. Comparative analyses of differentially induced T-cell receptor-mediated phosphorylation pathways in T lymphoma cells. Exp Biol Med 2010;235:1450-1463.

47 Wilcox RA, Sun DX, Novak A, et al. Inhibition of Syk protein tyrosine kinase induces apoptosis and blocks proliferation in T-cell non-Hodgkin's lymphoma cell lines. Leukemia 2010;24:229-232.

48 Geissinger E, Sadler $\mathrm{P}$, Roth $\mathrm{S}$, et al. Disturbed expression of the T-cell receptor/CD3 complex and associated signaling molecules in CD30+ T-cell lymphoproliferations. Haematologica 2010;95:1697-1704. 
49 Feldman AL, Sun DX, Law ME, et al. Overexpression of Syk tyrosine kinase in peripheral T-cell lymphomas. Leukemia 2008;22:1139-1143.

50 Steinberg M, Adjali O, Swainson L, et al. T-cell receptor-induced phosphorylation of the zeta chain is efficiently promoted by ZAP-70 but not Syk. Blood 2004;104:760-767.

51 Malissen B, Grégoire C, Malissen M, et al. Integrative biology of $\mathrm{T}$ cell activation. Nat Immunol 2014;15: 790-797.

52 Keller B, Zaidman I, Yousefi OS, et al. Early onset combined immunodeficiency and autoimmunity in patients with loss-of-function mutation in LAT. J Exp Med 2016;213:1185-1199.

53 Nuñez-Cruz S, Aguado E, Richelme S, et al. LAT regulates gammadelta $\mathrm{T}$ cell homeostasis and differentiation. Nat Immunol 2003;4:999-1008.

54 Archambaud C, Sansoni A, Mingueneau M, et al. STAT6 deletion converts the Th2 inflammatory pathology afflicting Lat(Y136F) mice into a lymphoproliferative disorder involving Th1 and CD8 effector T cells. J Immunol 2009;182:2680-2689.
55 Mingueneau M, Roncagalli R, Grégoire C, et al. Loss of the LAT adaptor converts antigen-responsive $\mathrm{T}$ cells into pathogenic effectors that function independently of the T cell receptor. Immunity 2009;31:197-208.

56 Rosenwald A, Alizadeh AA, Widhopf G, et al. Relation of gene expression phenotype to immunoglobulin mutation genotype in B cell chronic lymphocytic leukemia. J Exp Med 2001;194:1639-1647.

57 Chen L, Huynh L, Apgar J, et al. ZAP-70 enhances IgM signaling independent of its kinase activity in chronic lymphocytic leukemia. Blood 2008;111: 2685-2692.

58 Rassenti LZ, Huynh L, Toy TL, et al. ZAP-70 compared with immunoglobulin heavy-chain gene mutation status as a predictor of disease progression in chronic lymphocytic leukemia. N Engl J Med 2004;351: 893-901.

59 Facchetti F, Chan JK, Zhang W, et al. Linker for activation of $\mathrm{T}$ cells (LAT), a novel immunohistochemical marker for $\mathrm{T}$ cells, NK cells, mast cells, and megakaryocytes: evaluation in normal and pathological conditions. Am J Pathol 1999;154:1037-1046.

Supplementary Information accompanies the paper on Modern Pathology website (http://www.nature.com/ modpathol) 